$\underline{\text { Review Paper }}$

\title{
Multi-Dimensional Responsible Rural Tourism Capacity (RRTC) Framework: A Proposed Environmental Responsibility and Management Model for Malaysia
}

\author{
Vikneswaran Nair, \\ Taylor's University, Malaysia \\ Badaruddin Mohamed \\ Universiti Sains Malaysia, Malaysia \\ Lo May Chiun \\ Universiti Sarawak Malaysia, Malaysia
}

(C) The Author(s) 2015. This article is published with open access by Taylor's Press.

\begin{abstract}
Malaysia is regarded as a heaven for ecotourism and natural resources. Nonetheless, the very concept of ecotourism is confused with massive "greenwashing" that is destroying many pristine destinations especially in the rural settings. Various tourism models emphasising on the environment have been developed in the past in Malaysia with no holistic understanding of their impact to the natural environment. With this challenge in mind, this paper aims to understand and propose an environmental model that is able to balance the natural and economic environment in line with Malaysia’s Economic Transformation Programme where rural tourism is expected to alleviate from a low-yield to a high-yield economy. This will be achieved by developing suitable indicators to make the rural tourism business model sustainable. The first three years of the five year research (2011-2016) were involved in developing the fundamental aspects of the study, with emphasis on the establishment of baseline data and carrying out situational analyses at the ten selected study areas to help develop the indicators. The final two years will evaluate the performance of these sites using the developed indicators. Hence, this fundamental study is necessary to understand the various dimensions that are essential in investigating the relationships between different tourism models and how they are closely linked to the local economies and environments in key "natural" destinations in Malaysia.
\end{abstract}

Keywords: Rural tourism, responsible tourism, sustainable tourism, environment management, multi-dimensional

Correspondence: Vikneswaran Nair, Taylor’s University. Email: vicky.nair@taylors.edu.my 